\title{
Las resonancias del pasado: apuntes para un estudio diacrónico y sincrónico de una hinchada del fútbol argentino
}

\author{
The resonances of the past: notes for diachronic and synchronic study \\ of one football supporters group from Argentina
}

\author{
Nicolás Cabrera \\ Universidad Nacional de San Martín (UNSAM), San Martín / Argentina \\ Doutorando em Ciencias Antropológicas, Universidad Nacional de Córdoba (UNC) \\ nico_cab@hotmail.com
}

\begin{abstract}
RESUMEN: Las hinchadas -comúnmente conocidas como "barras bravas"- han devenido en un actor central de las prácticas y narrativas del fútbol contemporáneo. El escrito aquí presentado buscar comprender la mutación histórica de un caso específico de ellas a partir de una lectura en clave generacional. Tomando los relatos y las trayectorias de sujetos de tres generaciones diferentes de la hinchada estudiada, el trabajo se articula sobre dos ejes fundamentales que dialogan entre sí: por un lado proponemos una dimensión sincrónica que pretende mostrar la interdependencia constitutiva que existe entre la lógica organizativa que adquiere la hinchada, los patrones de legitimación que estructuran su organigrama interno y las prácticas y representaciones asociadas a la violencia que se dan en un momento histórico especifico; por el otro lado se presenta un eje diacrónico que busca leer en clave procesual y generacional los universos morales que posibilitan un complejo y dinámico repertorio de identificaciones, diferenciaciones y jerarquizaciones al interior de la hinchada a lo largo del tiempo.
\end{abstract}

PalABRAS Claves: Fútbol; Hinchadas; Violencia; Generaciones.

ABSTRACT: The members of argentine football supporters groups ("hinchada" or "barras bravas") have become a central actor of practices and narratives of contemporary football. This paper seeks to understand the historical mutation of a specific football supporters group from a generational point of view. Taking into account the testimonies and trajectories of subjects from three different generations of fans, the paper focuses on two fundamental axes that are related: on one hand we propose a synchronic dimension that aims to show the constitutive interdependence that exists between the organization of the fans, the legitimation patterns that structure their internal organization and the practices and representations associated with violence that occur in a specific historical moment; on the other hand a diachronic axis that tries to read in a procesual and generational key the moral universes that enable a complex and dynamic repertoire of identifications, differentiations and hierarchies within the football supporters group throughout the time.

KEYWORDS: Football; Hinchadas; Violence; Generations. 


\section{INTRODUCCIÓN}

La proliferación de estudios históricos en torno al fútbol que se ha dado en las últimas décadas, no ha tenido un correlato en el abordaje diacrónico sobre las "hinchadas".1 Poco sabemos sobre el origen y la mutación histórica de estos colectivos que a fuerza de cantos, banderas y golpes se han convertido en actores principales de las prácticas y narrativas futboleras argentinas. Creemos que este relativo vacío bibliográfico ${ }^{2}$ constituye un importante obstáculo para una comprensión en clave procesual de las distintas dinámicas sociales que atraviesan al fenómeno de las hinchadas argentinas. Este trabajo pretende ser un aporte en aquella dirección.

El escrito aquí presentado buscar comprender la mutación histórica de la hinchada del Club Atlético Belgrano de Córdoba ${ }^{3}$ a partir de una lectura en clave generacional. A partir de la reconstrucción de trayectorias y relatos de personajes de tres generaciones diferentes de la barra, el trabajo se articula sobre dos ejes fundamentales que dialogan entre sí: por un lado proponemos una dimensión sincrónica que pretende mostrar la interdependencia constitutiva que existe entre la lógica organizativa que adquiere la hinchada, los patrones de legitimación que estructuran sus diferencias y jerarquías internas y las prácticas y representaciones asociadas a la violencia que se dan en un momento histórico especifico; por el otro lado se presenta un eje diacrónico que busca leer en clave procesual e generacional los universos morales que posibilitan un complejo y dinámico repertorio de identificaciones, diferenciaciones y jerarquizaciones al interior de la hinchada a lo largo del tiempo.

\footnotetext{
${ }^{1}$ Cuando hablamos de "hinchada" nos referimos a un grupo de seguidores de un equipo de fútbol que se autoreconoce como colectivo y está fuertemente organizado. A lo largo del trabajo utilizaremos como sinónimos las nociones nativas de "hinchada", "barra" o "Los Piratas", con las cuales nuestros interlocutores se autoidentifican. Preferimos recurrir a esta terminología en reemplazo de la categoría mediática y estigmatizante de "barra brava". Todas las categorías nativas se referenciaran entre comillas.

${ }^{2}$ Como antecedentes directos que abordan específicamente los orígenes y las mudanzas históricas de las hinchadas argentinas encontramos los trabajos de Amilcar Romero (1986) y Mariana Conde (2006). EL libro de Julio Frydemberg (2011), si bien se reduce a Buenos Aires y no trabaja puntualmente sobre "hinchadas", es una lectura imprescindible para comprender el escenario socio-cultural que posibilito la formación de dichos colectivos.

${ }^{3}$ El Club Atlético Belgrano, creado el 19 de Marzo de 1905, tiene su estadio en Alberdi, un barrio popular cercano al casco céntrico de la ciudad de Córdoba, Argentina.
} 
Los datos aquí analizados fueron construidos a partir de una perspectiva etnográfica que orientó un trabajo de campo desarrollado entre finales del año 2010 y finales del año 2015, con un receso anual durante todo el 2013. La experiencia etnográfica se basó en acompañar y registrar -mediante observación participante y entrevistas semiestructuras- las prácticas y representaciones de los miembros de la hinchada de Belgrano, tanto cuando acompañaban al equipo profesional de fútbol los días de competición, como en algunas situaciones cotidianas que no tenía "a la cancha" como epicentro.

\section{LOS PIRATAS: "LA PRIMERA BARRA"}

El primer antecedente de un grupo de hinchas fuertemente organizados en torno al equipo de fútbol de Belgrano bajo una auto denominación colectiva existió a finales de la década de 1950 y se llamó "La barra del pito", en honor a una especia de silbato-flauta que algunos de sus miembros llevaban para "animar" en la tribuna. Los miembros de "La barra del pito" eran todos socios de club. Durante los partidos se congregaban en la tribuna "platea", sin superar los quince miembros aproximadamente. Todos ellos eran hombres mayores de edad que, en los días de semana, solían reunirse en las instalaciones del club.

En 1968 Belgrano accede a jugar por primera vez un torneo Nacional de la Asociación del Fútbol Argentino (AFA). Esto implicaba que el equipo profesional comenzaría a jugar contra equipos de otras provincias. El nuevo escenario no sólo incrementó la cantidad de espectadores en las tribunas sino que demandó una mayor organización de la hinchada. Es en este marco que nace, en 1968, "La barra de Los Piratas". Aunque existen diferentes versiones sobre el momento inaugural de la hinchada, la "oficial" fecha la fundación de la barra el 9 de julio de 1968, en el Bar de Zingarella -otros dicen que fue en una ferretería- ubicado en la calle Arturo Orgaz. Allí se reunieron sus primeros integrantes, labraron un acta y fundaron Los Piratas. Esta hinchada se transformaría en "la primera barra de Córdoba" y, para muchos, en "la primera barra del país" ya que era la única que viajaba a otras provincias a "alentar" a su equipo. 
En cuanto las razones de la nominación "Los Piratas", la pluralidad de versiones resiste cualquier intento de precisión histórica. Aquí sólo podemos decir que en todas ellas el nombre se vincula a ciertas prácticas asociadas a la transgresión -por ejemplo, el robo y saqueo a almacenes que se encontraban en las rutas- o a códigos normativos que prescriben relaciones de solidaridad entre los pares.

Aquellos orígenes de la hinchada operan como un mito fundacional permanentemente recuperado, reactualizado, disputado, resignificado y hasta negado en el ejercicio de memoria de las generaciones subsiguientes. Se trata de un primer significante imprescindible para comprender lo que Elizabeth Jelin define como la función política de la memoria: una permanente disputa por el sentido de un pasado que estructura el presente y que condiciona los procesos de (re)construcción de identidades individuales y colectivas. ${ }^{4}$

\section{El POLACO: LA PRIMERA GENERACIÓN}

El Polaco entra en compañía de un bastón. Su caminar tiene un ritmo que confiesa inmediatamente sus ocho décadas de vida. Nació en el barrio de Alberdi pero se creó en Providencia, un barrio de clase trabajadora que colinda con Alberdi, donde vivió hasta los 16 años. Durante esa época iba con un "grupito de amigos del barrio" a la cancha todos los domingos y se "colaban" por el baldío que daba a la tribuna de la calle Hualfín. En 1967, con el club próximo a ingresar al torneo nacional, El Polaco vuelve a la cancha. Dos años después, él comienza a reunirse con Los Piratas principalmente en las previas del partido y en las reuniones semanales que ellos tenían en el Bar de Luna -un boliche debajo de la tribuna popular local del estadio que hacía las veces de punto de encuentro del grupo.

Las actividades de la barra comenzaban varias horas antes del partido. La "previa" empezaba tres o cuatro horas antes del encuentro, preparando bombos, redoblantes, trompetas, banderas y "papelitos" para tirar en el recibimiento al equipo. Allí también se ensayaban, entre asado y alcohol, canciones para entonar en la tribuna.

\footnotetext{
${ }^{4}$ JELIN. Los trabajos de la memoria.
} 
Durante el cotejo deportivo la Barra de Los Piratas se ubicaba en la tribuna "popular", detrás de uno de los arcos del campo de juego. Esto marca una primera diferencia con la "Barra del pito": como dice El Polaco, mientras que esta última era "una barra de platea", Los Piratas era "gente más popular". Ya en esa época existía un diferencial monetario entre el costo del ingreso a la "platea" y el de la "popular" que se traducía en una distinción de origen social de los asistentes.

Además de los momentos de socialización en las previas, durante y luego de los partidos, existían reuniones semanales que convocaban a los integrantes de la barra los días jueves en el Bar de Luna. Allí, entre música y bebidas, se discutían cuestiones organizativas internas de la barra, en un clima que El Polaco describe como "totalmente democrático":

\begin{abstract}
-Sí, era todo tan democrático, Nicolás... era todo tan democrático... no como ahora ¡Se votaba! Se votaba, se hacía una lista [de a] quién podíamos elegir de presidente. Y nosotros votábamos. El flaco Mario Cardozo estuvo un montón de tiempo, como dos o tres periodos estuvo. [Él] era un... no era un grandote, un oso, un monstruo... ¡No! Era un flaquito que no le hacía mal a nadie ni le pegaba a nadie, ni ofendía a nadie. Era una dulzura de tipo... ese era el presidente de Los Piratas.
\end{abstract}

La descripción del "flaco Mario" centrada en su "dulzura", en su no apelación a la fuerza y la insistencia en el carácter "democrático" de la reunión para la elección de autoridades traza una frontera que se vuelve inteligible como totalidad en su discurso sobre las prácticas violentas: una línea divisoria entre la "vieja" forma, democrática y pacífica, y una "nueva” forma, basada en la fuerza y el autoritarismo

\footnotetext{
-¡Había una sola lista! [...] y allí este... una noche habían elegido ya el presidente y estaban eligiendo los demás cargos para abajo, vocales, y me dice El Negro Cábala, uno de los bombistas, eh... me dice... Polaco, porque ese era el apodo que ellos me habían puesto... "¿Vos querés integrar la comisión directiva?” ¡Sí! Le digo ¡Si siempre vengo! ¿Cómo no voy a querer integrar la comisión? Bueno, y me anotaron. Entonces allí, este... fui incluido en esa comisión eh... año `69, o sea, un año después que los piratas se... Bueno, y ahí empezó que yo también empecé a viajar con ellos, a compartir muchos viajes, muchas historias, muchas vivencias.
}

La lógica organizativa de la hinchada tenía un organigrama de tipo asociacionista que emulaba el formato jurídico-social de los clubes como asociaciones civiles sin fines de lucro. Había presidente, vicepresidente, secretarios, tesorero y vocales, todos elegidos "democráticamente" y postulados en 
lista única. Esto no significa que no existiesen subgrupos o "filiales", pero todas ellas se aglutinaban bajo una lista que representaba la totalidad de las facciones. Los criterios colectivos de evaluación y los patrones de legitimación sobre la elegibilidad en cargos de "dirección" habrían residido fundamentalmente en la evaluación del "compromiso con la barra", la asiduidad en los eventos propios de la hinchada, la "solidaridad" con los pares y cierta idoneidad para cuestiones logísticas (como la organización de eventos recaudatorios para financiar las actividades y elementos de la hinchada).

\section{SOCIABILIDAD Y VIOLENCIA}

Los viajes que Los Piratas realizaban por todo el país, acompañando las presentaciones del equipo profesional del club, funcionaban como rituales de gran importancia en torno al afianzamiento del sentido de pertenencia grupal, al mismo tiempo que delimitaban identificaciones, diferenciaciones y jerarquías hacia el interior de la barra. Los largos recorridos interprovinciales operaban como espacios vitales de sociabilidad y, al mismo tiempo, como instancias de evaluación colectiva sobre el nivel de fidelidad y compromiso de sus integrantes con el club y con la hinchada.

Al mismo tiempo, el origen de clases populares de muchos de los integrantes de la barra que salían por primera vez de la provincia de Córdoba en estos eventos, tiñe la experiencia de un fuerte valor material y simbólico: el conocimiento de lugares y ciudades relativamente inaccesibles por otros medios. El mismo Polaco nos decía que los viajes eran "experiencias muy gratas porque fueron las únicas veces que yo he salido a otra provincia".

Los viajes nos aparecen, al mismo tiempo, como llave metodológica de ingreso a los universos morales de la generación del Polaco y de las fronteras que él construye con las generaciones siguientes: la dimensión del interés económico en la barra y las prácticas de violencia en su relato.

El Polaco es enfático al trazar el límite: "muchas cosas que no eran como ahora". Marcando una fuerte discontinuidad con el presente, aclara que "en aquellas épocas" la barra conseguía sus propios recursos (económicos) rifando 
pelotas, camisetas, asados u organizando peñas. Si bien El Polaco nos aclara que no quiere referirse a los "negocios" de ahora pero en la enfática positivización del carácter autogestivo de la antigua barra se trasluce cierto rechazo a las supuestas actividades clandestinas con las que la barra se financiaría actualmente.

La diferenciación es más taxativa aún en cuanto a los sentidos en torno a la violencia. El Polaco reconoce su participación en varios enfrentamientos de la barra, aunque los define como "casos aislados". En más de una ocasión comenta que cuando jugaban contra otros equipos locales en Alberdi -incluido el Club Atlético Talleres ${ }^{5}$ la hinchada visitante pasaba caminando por la misma tribuna que la local sin que esto generara ningún altercado. Relata, además, que entre las "cúpulas" de las barras existía "buena relación" y entre el resto de los hinchas había "cargadas normales, pero de boca nada más, nada de ofensas, ni de riñas, ni de amenazar [...] era un partido de fútbol y nada más".

El discurso nativo de esta generación no niega la existencia de fenómenos violentos, aunque regulados por rígidos códigos de conducta fundados en cierta moralidad masculina de la caballerosidad y el honor (sobre los motivos legítimos para una "reacción" violenta, siempre defensiva, nunca promotora del conflicto físico), y más explícitamente en mecanismos civilizatorios autorreguladores ${ }^{6}$ que diferencian esta generación del tipo de violencia que practicarían las generaciones sucesorias.

-Acá en Belgrano nada que ver, no sé en la hinchada de Talleres, de Instituto, en otros equipos no sé, pero acá en Belgrano te digo ¡Los Piratas del `68 eran señores!, Señores... no robaban, no peleaban... por ahí, bueno, si alguno se ofendía, bueno, algún par de piñas había [...] la barra de Belgrano, ir a provocar un desorden, una pelea, no...

“Los Piratas del '68" eran "señores", no por rehuirle al enfrentamiento físico, sino porque ejercían la violencia en condiciones defensivas y bajo parámetros normativos, como el uso exclusivo del cuerpo como herramienta de combate y la negativa a utilizar armas de fuego o armas blancas, en conflictos

\footnotetext{
${ }^{5}$ El Club Atlético Talleres es el "clásico" histórico de Belgrano. Entre ambos equipos existe una histórica rivalidad que progresivamente se fue trasladando a las tribunas, esta disputa entre hinchas va desde humoradas cotidianas hasta enfrentamientos violentos cuerpo a cuerpo, principalmente desde comienzos de la década del setenta y ochenta hasta la actualidad.

${ }^{5}$ Cf.: ELIAS. El proceso de civilización (1993).
} 
caracterizados como absolutamente contingentes y localizados, sin propagación más allá de los límites espacio-temporales de la riña.

\begin{abstract}
-En aquellos años, porque yo también estoy con setenta años encima, en aquellos años en las canchas, yo creo que esto fue toda la vida, que siempre hubo algún desacuerdo, desentendimiento y venían la piñas; pero en aquellos años, era una diferencia abismal con hoy... eran trompadas limpias, se terminaban las trompadas y no se usaban armas. Terminaban las trompadas bueno cada uno a su casa. [...] Eran peleas, digamos, de hombre, se sacaban la bronca del momento a trompada limpia ¡Y chau! Cada uno a sus casas, no era como ahora que balas, armas de fuego, cuchillo [...] Al otro domingo a lo mejor nos encontrábamos de nuevo o a lo mejor nos abrazábamos a las risadas o a lo mejor jugábamos normal como si no hubiera pasado nunca nada. Así era antes. Ahora ya no, ahora hay una especie de odio, de rencor, de... no sé cómo... digamos... se ha perdido la cultura deportiva.
\end{abstract}

Este universo moral, generacionalmente asociado al Polaco, se encarna y cristaliza en lo que él define como la "cultura deportiva": un mundo de la hinchada en espejo al mundo del campo de juego, con reglas de "juego limpio", con formas de violencia "limpia", "sana", "medida", "regulada". Una violencia fuertemente normativizada e higienizada que estaría inmaculada de las distorsiones propias de "la violencia de hoy". Esto pone de manifiesto la complejidad del relato nativo sobre la violencia, que antes que interdicciones absolutas propone apreciaciones con fronteras de legitimidad y tolerancia móviles, singulares y localizadas.

\title{
CARLOS: SEGUNDA GENERACIÓN
}

La charla es intermitente y poco fluida. En menos de veinte minutos de entrevista, Carlos saludó a varias de las personas que pasan por la plaza: “a mí me conoce todo el mundo", nos dice con una sonrisa llena de picardía y soberbia. Para recibirnos, "se hizo un tiempo" en el trabajo. Es empleado del estado municipal de Córdoba desde el año 1988, gracias a los contactos que supo cultivar con el radicalismo ${ }^{7}$ desde el retorno a la democracia. Según Carlos, este "contacto" se forjó en sus años con la hinchada. Con cincuenta y cinco años de vida, Carlos tiene una trayectoria en

\footnotetext{
7 "Radicales", en Argentina, refiere a los miembros del partido politico Union Civica RadicalUCR.
} 
la barra tan ecléctica como constante. Hace más de veinticinco años forma parte de la hinchada pero fue perteneciendo a distintas facciones dentro de la barra.

Carlos comenzó a frecuentar la cancha de Belgrano a fines de la década de 1960. Con 12 años de edad, se las ingeniaba para entrar gratis al estadio junto con su amigo Pablo. Su aproximación a la barra se dio cerca de 1980, de la mano de un grupo conocido como "La banda de la Bajada", en referencia a una villa miseria8 conocida como "La Bajada", un asentamiento cercano al club donde Carlos vivió durante varios años. Esos comienzos, sobre todo con el retorno de la democracia, son rememorados por nuestro interlocutor como "tiempos de guerra", debido a la permanente y sistemática violencia que atravesaba a la hinchada. Los principales contrincantes eran las barras de diferentes equipos y la policía, aunque ocasionalmente también existían conflictos internos esporádicos. "La banda de la Bajada" era, según Carlos, "un bandón de la concha de su madre", "muy respetada" por su ferocidad en los enfrentamientos físicos: "los vagos tenían en mente solamente pelear, pelear, pelear... no había cabeza de grupo". Según Carlos, "La Bajada" era reconocida en la hinchada por el "descontrol" de sus miembros, principalmente en referencia a sus competencias corporales para el combate físico y al consumo habitual de estupefacientes ilegales y alcohol. Según su relato, tenían un "cartel ${ }^{9}$ [que hacía] que el mundo le tuviera miedo a la Banda de la Bajada y nosotros éramos, más o menos, cincuenta monos que se paraban los cincuenta". El mismo Carlos, haciéndose eco de ese "ciclo", se describe a sí mismo retrospectivamente:

[Un] barderazo bárbaro. Tenía veinte y pico de años, por eso te digo, todo tiene su ciclo. Si vos me decís ahora, yo ahora no me chupo, no me drogo, nada, nada, de nada. Pero antes, de los trece hasta los... cuarenta y pico, he chupado, he tomado merca, he sido un loco de la guerra bárbaro [...] Yo era conocido por ir al frente, por el aguante.

\footnotetext{
${ }^{8}$ Nominación popular con la que se conoce a los asentamientos informales urbanos que en Argentina empezaron a construirse a partir de la década del treinta del siglo XX aproximadamente.

9 "Cartel" es una metáfora nativa que refiere a la supuesta fama o reconocimiento que otros dan a cierto grupo o persona.
} 
Carlos parece ser un claro exponente de lo que muchos autores han definido como la "lógica del aguante"10 en tanto sustento legitimador de las prácticas violentas que estructuran a las hinchadas argentinas. "Tener aguante" -y demostrarlo efectivamente- significa poseer una actitud corporal que no sólo no rehúsa los enfrentamientos violentos, sino que los provoca y los valora positivamente. Apoyado en complejas nociones vinculadas al género -la pelea como forma de afirmar la masculinidad-, los territorios - una cartografía dividida en territorios propios y enemigos-, ciertos consumos -inversión de los estigmas sobre las drogas y el alcohol- y una fuerte retorica belicista -"tiempos de guerra"-, la noción de "aguante" resulta útil para caracterizar todo un período donde la violencia física fue ganando terreno en tanto recurso de valor, prestigio, reconocimiento y respeto al interior de las hinchadas.

\section{VIOLENCIA Y FRAGMENTACIÓN}

En 1984, tras un partido jugado en entre Atlético Tucumán y Belgrano en la provincia de Tucumán, un hincha del equipo local es asesinado de una puñalada en la tribuna donde se concentraba la barra de Belgrano. Tras ese episodio, Carlos termina preso identificado en el episodio a partir de una foto publicada en el periódico La Gaceta. Después de aquel acontecimiento, él y Pablo, su amigo de la infancia, fundan una nueva facción de Los Piratas llamada "La 2004". Carlos justifica la necesidad de esta agrupación en su disconformidad con "los manejos de dinero" que realizaba El Cabezón Jorge, líder de una facción de Los Piratas que llevaba su nombre y a la cual pertenecía el grupo de "La Bajada”. Según Carlos, con Pablo pudieron convertirse en líderes de "La 2004" por su "fama de guapos".

Desde mediados de la década de 1980 comienzan a sedimentar dos características fundamentales de Los Piratas que, según Carlos, se extenderían durante las subsiguientes décadas de 1990 y 2000: primero, un alto nivel de violencia localizada principalmente en los estadios o sus adyacencias, durante los

\footnotetext{
${ }^{10}$ Cf.: ARCHETTI. Fútbol y Ethos. ALABARCES. Crónicas del aguante. GARRIGA. Haciendo amigos a las piñas. MOREIRA. Trofeos de guerra y hombres de honor. GIL. Hinchas en tránsito.
} 
días de partido o en los viajes que la hinchada realizaba por el país. Esta violencia y el desarrollo de una enorme capacidad para su ejercicio son axiológicamente positivizadas en el discurso de los miembros de esta generación. Un grupo que peleaba constantemente se consideraba digno de "respeto" - "cartel"- y era reconocido por sus pares. Alguien con "fama de guapo" o "aguante" -como Carlos o Pablo- accedía, por ello, a la posibilidad de liderar una facción.

En segundo lugar, se observa que la estructura organizativa interna de la barra va asumiendo una forma en la que predomina la heterogeneidad de grupos, facciones y liderazgos que, aún identificados bajo el nombre de "Los Piratas", no estaban exentos de conflictos internos y reconfiguraciones permanentes. Existe, en esta época, una dispersión de la hinchada que la asemeja a un archipiélago de grupos que responden a liderazgos disimiles, valorados fundamentalmente en función de las prácticas violentas.

\section{ENTRE LO “VIEJO" Y LO “NUEVO”}

Desde la fundación de "La 2004", Carlos ocupó una posición jerárquica en la barra de Los Piratas en tanto líder de aquella facción. Desde el año 2004, el grupo cambia de nombre a "La 19 de marzo", en referencia al día del aniversario del Club Atlético Belgrano. Carlos estuvo al frente de este grupo hasta que, en el período 2011-2012, la hinchada entra en un proceso de reorganización interna que termina con la monopolización de la tribuna por una sola facción y la expulsión de "La 2004". Nos detendremos en la visión de Carlos sobre la mutación que presenció en los últimos años en relación a las lógicas de la hinchada y las transgresiones asociadas a ella.

El proceso de reconfiguración de la barra se narra en clave de conflicto intergeneracional. Carlos construye una mirada despectiva sobre las prácticas y los consumos de los integrantes más jóvenes de la hinchada. Los describe como personas "sin códigos" ("quieren ir a picotear ${ }^{11}$ a cualquiera") e imprevisibles en cuanto a normas de conducta, y justifica su diagnóstico con el relato y la descripción de sus propios consumos y prácticas de transgresión:

\footnotetext{
11 "Picotear" es una noción nativa que refiere a la acción de golpear ferozmente a uno o a pocos sujetos que se encuentran en clara inferioridad numérica en relación a sus agresores.
} 


\begin{abstract}
-[Hoy] se viene toda la guachada, que está toda perdida, está toda drogada, está toda alcoholizada. Entonces, no le importa un... "andá a hablar"... ¡Nada, las pelotas! Están dados vuelta [...] el querer ir a picotear a cualquiera persona, ir a sacarle cualquier cosa, porque si no más, por el estado en la cual está ¿Me entendés? Y como están todos iguales, no saben lo que hacen, no saben lo que hacen. Yo he visto cada cosa en los baños y he parado broncas... Viejitos que van a la popular, que de pronto se van al baño, porque se quieren echar una meada y se llevan la radio, porque son esos viejos de oreja de coso (imita con la mano en la oreja) y sí... le sacan la radio ¿sabés las veces que le he hecho devolver las cosas? Vos no sabés. Esos códigos antes, no se hacían, no existían [...] calculá, hoy se perdió todo, hoy no existe nada. Por eso se hace muy difícil también controlar. Hoy por hoy, no son los pibes que eran hace veinte años atrás.
\end{abstract}

Carlos marca un quiebre abrupto entre los "códigos de antes" y las prácticas de "hoy". Los jóvenes de la barra se perciben como "incontrolables". El contexto se tiñe de una violencia creciente que no se regula por los antiguos preceptos normativos (la prohibición moral de robar en la tribuna y a los propios hinchas de Belgrano o a personas adultas mayores) y que se agrava por el consumo desmedido de alcohol y drogas. Carlos traza una frontera moral entre generaciones, a partir de la cual los "jóvenes de hoy" se definen como un grupo caótico, incomprensible, violento, vicioso, "perdido", debido a su violencia desenfrenada y su falta de respeto por las jerarquías de la hinchada.

El discurso contencioso a partir del cual estos procesos de diferenciación se generan no sostiene linealidad ni consistencia lógica. Las prácticas que Carlos condena entre los jóvenes actuales en la barra no difieren demasiado de las propias experiencias de "descontrol" que narra sobre sí mismo en su juventud. En este sentido, lo que Carlos expresa no es tanto un juicio moral contra las prácticas de transgresión de los jóvenes, sino un proceso de descalificación simbólica a partir de sistemas clasificatorios de matriz moral. En otras palabras, lo que está en juego en su narrativa no es la valorización del orden social imperante en la tribuna, sino las disputas generacionales actuales en el interior de la hinchada.

Por otra parte, la ambivalencia que condensa todo el testimonio de Carlos sobre las prácticas violentas - ayer positivizadas, hoy condenadas - no puede ser reducida ni a una disputa generacional ni a una metamorfosis biográfica-personal. Estos “desajustes" responden, principalmente, a que a Carlos le tocó experimentar un momento bisagra en la construcción de los patrones valorativos que 
estructuran la organización interna de la barra. Se trata de un momento de transición entre patrones de legitimación diferentes a la hora de estructurar las membrecías y jerarquías propias de la hinchada; una convergencia de dos procesos que parecen estar indisolublemente ligados.

La denostación discursiva de los más jóvenes como "agentes del caos" cristaliza el ocaso de un período en el que la capacidad de combate, el uso desproporcionado de la fuerza y el "aguante", eran considerados como los principales recursos legitimantes para acceder a posiciones de liderazgo y jerarquía en la estructura organizativa de la barra.

Por otro lado, los relatos de Carlos muestran la identificación de un cambio en los patrones valorativos de liderazgo que tendieron a cierta racionalización civilizatoria de la organización. En los últimos años el uso de la "fuerza" como capital vital de los líderes de fracciones va dejando lugar al recurso de la "cabeza" de los referentes de la barra. El principio legitimador de la autoridad en la hinchada parece desplazarse de las competencias corporales para las prácticas violentas hacia las cualidades vinculadas a los "tratos interpersonales", la capacidad de construir redes de reciprocidad, obtener recursos monetarios y la "inteligencia" para resolver conflictos sin necesidad de echar mano al recurso de la fuerza.

\footnotetext{
-Llegaron otros tiempos, porque cambiaron de dirigentes [el club], en donde no era el más fuerte el que iba a pelear, el que iba a llevar todo por delante. No. Si no [que] era más fuerte el que era más inteligente y en eso, le sacaba varias cabezas a un montón. Muchas veces por esto, por esto, porque te vas haciendo de mente... [Y] de contactos ni hablés ¿sabés lo que vale esta agenda? [...] Yo hablo con cualquiera de los jugadores actuales. Debo tener de diez jugadores contactos. Sé cuánto cobra cada uno, qué es lo que dejan, a quién se lo dejan, a dónde dejan la coima... eh... qué pasa internamente. Hay muchas cosas que el común de la gente, el hincha, no sabe.
}

\section{MAURO: TERCERA GENERACIÓN}

En el cuarto de Mauro no hay ni un rincón que descanse del color celeste. “Belgrano" decora cada centímetro de la habitación en la que vive desde que nació junto a sus padres y hermanos. En igual proporción que al club, la parafernalia decorativa refiere a la simbología de "Los Piratas celestes de Alberdi (en adelante 
LPCA): la primera barra". ${ }^{12}$ Como él mismo lo expresa: "Soy más hincha de la barra que de Belgrano".

Con 28 años de edad, Mauro es el "referente" máximo de la "música de la barra": organiza el grupo de los bombos; junto con Turi coordinan los "vientos" y con Pato inventan las canciones y deciden su secuencia durante los partidos. Mauro también diseña y vende ropa de la barra. Él es joven en relación a la jerarquía que posee en la hinchada. Sus allegados lo describen como una persona inteligente, con firme voz de mando, compromiso total con la barra y con lazos familiares con personajes "históricos" de la organización: Mauro es la tercera generación de su familia que participa activamente en la barra. Su padre, miembro de Los Piratas durante décadas, hoy cercano a los 60 años de edad, fue quien les transmitió a él y a su hermano mayor la doble pasión por Belgrano y por la barra.

\begin{abstract}
-Bueno, lo de Belgrano es familiar, está en la sangre, yo ya tengo el gen pirata desde que nací. Mi viejo era de Belgrano y de chiquito me lo inculcó, del hecho de comprarme todo celeste, o cuidar de no tener nada azul. ${ }^{13}$ Por ejemplo, no me compraba la ropa deportiva Adidas porque era azul y blanca [...] Y al principio mi viejo no me llevaba. Pasa que la cancha cambió mucho. Antes había mucho bardo, había cosas que no se podían ver y él estaba con la barra, entonces él no me llevaba todos los partidos. [...] Casi siempre fui a la popu, pero viste que antes no estaba lo de los carnet ni los socios, entonces a veces mi viejo sacaba platea o preferencial pero casi siempre en la popu. Mi viejo me llevaba y me quedaba en el para-avalancha principal del viejo, ahí quietito y no me dejaba moverme de ahí. Yo miraba más a los locos parados en los caños que al partido: yo quería estar ahí.
\end{abstract}

Mauro percibe un cambio abrupto en la dinámica de la hinchada en los últimos años. Un primer elemento de esta transformación es la reconfiguración interna del organigrama Pirata. Hasta el período 2010-2011, en la hinchada de Belgrano convergían cinco facciones: "LPCA" que es la facción más antigua y está encabezada por el Loco Beto; 14 "La 19 de Marzo”, comandada por Carlos (visto aquí como la "segunda generación") y su amigo Pablo; "La banda del Jetón Marcos", con líder homónimo; "La Barra de Chocu y Javier”, en referencia a quienes habían sido

\footnotetext{
12 "Los Piratas Celestes de Alberdi "(LPCA) es una facción de Los Piratas que reconoce una filiación directa con "Los Piratas del 68", la primera generación de Los Piratas que aquí personificamos en el Polaco

${ }_{13}^{13}$ Uno de los colores del principal equipo rival: Talleres.

${ }^{14}$ El Loco Beto es un personaje de rango casi mítico en el universo moral de la hinchada. Comanda la facción LPCA hace más de veinticinco años y desde aproximadamente 2010 es el líder máximo de la hinchada por la posición hegemónica de su propio grupo.
} 
sus antiguos jefes; y "La Fraternidad", liderada por el Flaco Rubén. Todos los grupos anteriormente nombrados conformaban la hinchada de Belgrano, autodenominada Los Piratas.

Si bien entre las distintas facciones parecía haber una paz inestable interrumpida por esporádicos enfrentamientos internos, había un precario acuerdo acerca del lugar y el peso de cada grupo: LPCA ocupaban la posición de "establecidos",15 mientras las otras cuatro facciones quedaban relegadas a posiciones marginales. A pesar de esta convivencia relativamente pacífica, todos nuestros interlocutores percibían a la tribuna popular como un territorio profundamente violento e "incivilizado".16 En las entrevistas y registros etnográficos correspondientes a dicha etapa son recurrentes las referencias a robos, enfrentamientos violentos contra la policía o contra las hinchadas de los equipos adversarios, peleas esporádicas entre hinchas de Belgrano, prácticas agresivas contra las mujeres en la hinchada, consumo permanente y público de sustancias ilegales, desorganización para las puestas en escena desplegadas en la tribuna y una relativa vacancia de autoridades fuertes en la hinchada.

Entre los años 2011 y 2012, aquel orden social simbolizado como "anómico" fue fuertemente trastocado cuando LPCA comenzó una ofensiva de monopolización territorial basada en la expulsión violenta de las otras facciones de la tribuna popular Este proceso implicó un incremento de los enfrentamientos violentos ocurridos en este espacio durante días de partidos ${ }^{17}$. Todas estas peleas tuvieron una dinámica similar: enfrentamientos cuerpo a cuerpo que disputaban la ocupación de la espacialidad de la facción derrotada y su expulsión de la tribuna. De esta manera LPCA "corrió" de la "cancha" una por una al resto de las facciones hasta hacerse del control total de la tribuna popular. Esto no significa que la violencia entre facciones haya desaparecido, sino que fue desplazada, privatizándose ${ }^{18} \mathrm{y}$

\footnotetext{
${ }^{15}$ ELIAS; SCOTSON. Os estabelecidos e os outsiders.

${ }_{17}^{16}$ ELIAS. El proceso de civilización.

${ }^{17}$ Es muy importante recalcar que este aumento exponencial de los enfrentamientos internos entre facciones de Los Piratas se da en el marco de la prohibición del público "visitante" decretada por el Estado Nacional a partir del año 2006 para los torneos de ascenso y a partir del 2013 también para la primera división del fútbol argentino.

${ }^{18}$ El concepto de "privatización de la violencia" es utilizado en el sentido empleado por Elias (1993) y Spierenburg (1998). Este no refiere a la transferencia del monopolio de la violencia física del Estado a sectores privados producto de una hipotética mercantilización, sino como el
} 
desarrollándose "detrás de bastidores",19 en momentos y espacios ajenos a los espectáculos deportivos estrictamente considerados. ${ }^{20}$ Esto conllevó un correlativo aumento exponencial de las disputas entre facciones del mismo club en detrimento de los enfrentamientos contra policías o hinchadas de equipos rivales. También aumentó comparativamente la cantidad de víctimas fatales, en parte por el aumento de los enfrentamientos, en parte por el mayor uso de armas de fuego.

La nueva figuración de Los Piratas, bajo el dominio y monopolio de LPCA, se caracteriza por un orden de pacificación fundado en el monopolio de la violencia por parte de la facción triunfante y un consiguiente rechazo contra (otras) expresiones de violencia física en la tribuna. De esta manera, LPCA asume metonímicamente la representación como unidad totalizante de la hinchada de Belgrano, refundando los lazos de interdependencia entre "establecidos" y "outsiders", ya no como "facciones" en disputa sino como "subgrupos" de LPCA.

En este período de violencia privatizada y tribuna monopolizada y pacificada, los cambios más sustanciales en torno a la hinchada se organizan en dos ejes: los umbrales de tolerancia a distintas expresiones de violencia y los patrones de legitimación que estructuran los principios de autoridad internos en la hinchada.

\section{"LA VIOLENCIA YA NO VA"}

Mauro nos muestra un recorte de diario del año 2001. En la foto se reconoce el Loco Beto, líder de LPCA, rodeado de varias personas. Mauro nombrar uno por uno a los de la foto y marcando con el dedo índice nos cuenta: "Ahí está mi hermano y ¿Ves ese gordito? Soy yo. Era una época muy distinta a la de hoy".

Cambió el ambiente. Antes era más pesado, y eso cambió. No sé si también cambió la sociedad, que ahora estamos mejor. [...] Hoy cambió por ejemplo la inserción de la mujer: antes vos tenías tres o cuatro viejas en la cancha. Hoy va la familia, está lleno de minas, si antes pasaba una sola mina toda la tribuna le

aumento de los umbrales de intolerancia a la violencia en la vida pública cotidiana -tomando a los estadios durante los días de partido como el espacio público por excelencia del fútbol en general y la hinchada en particular. El concepto refiere al proceso en el que la violencia se traslada "detrás de bastidores" (Elias, 1993, p. 64).

${ }^{19}$ ELIAS. El proceso de civilización.

20 Después de la expulsión violenta de la tribuna por parte de una facción sobre las otras, algunas de ellas se siguieron enfrentando en espacios como bares, recitales, bailes de cuarteto, clubes barriales, domicilios privados, adyacencias de los estadios, entre otros. 
cantaba "culeadora, culeadora". [...] El otro día tuve que sacar un guaso de entre medio de los bombos porque estaba sacando fotos, fui y le dije "loco no podes sacar fotos". Se lo dije bien pero el tipo estaba ahí sacando fotos. Antes, imagínate, le choreaban la máquina. Lo del robo también fue un cambio grande. Antes la barra entraba a la cancha y la silbaban. Ahora muchos parecen más hinchas de la tribuna que del equipo.

Mauro narra una tribuna sin robos, sin acoso a las mujeres y sin los niveles escandalosos de consumo de sustancias que se observaban en períodos anteriores. En su relato se invisibilizan los enfrentamientos internos de la hinchada, mientras que esta última cobra aceptación y legitimidad entre la mayoría de los simpatizantes del club. Este proceso se erige simbólicamente bajo la idea de "la vuelta de la familia a la cancha": una hinchada que es también lugar para los niños, las mujeres y los adultos mayores. Algo impensado en el período anterior, retratado en el relato de Carlos. En la misma línea, el discurso enfatiza la mayor relevancia del grupo de música en la hinchada, con su estética "carnavalesca" y "fiestera", proporcional a la pérdida de valor de la capacidad de combate en los estadios.

La violencia ya no va, está muy condenada, ya no va más. Vos fíjate las canciones. Hoy tienen frases que te llegan al alma, antes era "tomo pala, ando con fierro, no te parás". ¿Cómo le explicás a una familia que cante eso? Si yo canto ese tema lo van a cantar dos o tres rochas y nada más. Cambia el público de la cancha y también cambian los temas. Ahora es cantar desde el sentimiento.

\section{“DE LA FUERZA A LA CABEZA"}

Mauro remarca y enfatiza algo que ya había esbozado Carlos para los finales de su periodo: que el "uso de la fuerza" continúa siendo un recurso válido, deseado y legítimo para construir autoridad y liderazgo dentro de la hinchada. De igual manera, la "trayectoria" en la barra y el "compromiso" demostrado aparecen como patrones de legitimidad complementarios.

En el relato de un "nuevo escenario", con una tribuna más propensa a "la fiesta" que a la "violencia", habilidades alternativas como la inteligencia, la logística organizativa y la capacidad para construir y movilizar contactos y redes de intercambios recíprocos parecen cotizar en alza. 


\begin{abstract}
-[Para ser referente] tenés que tener lucidez, liderazgo, sino tenés eso, chau. Y tenés que tener trayectoria, si no te cagaste de frío, si no viajaste, si no te cagaron a balazos de goma, si no te quebraron en Colón... tenés que tener historia. Yo por ejemplo, yo soy muy, muy ... ¿Cómo se dice [se lleva la mano a la cabeza marcando el signo del pensamiento]? Muy de estar carburando siempre. Siempre pensando. Siempre trato de estar un paso adelante, en la cancha, en el trabajo. Si me agarras colgado es que estoy pensando. Aprendí a pensar antes de hablar. Eso es importante, eso lo aprendí de mi viejo.

ER: ¿Y a vos no te gustaría manejar la barra?

-Sería lindo, pero no, no tengo carácter. La maldad no la tengo. Ojo, no tengo nada contra el que lo hace, pero yo sí tengo cosas que perder. [...] Antes vos te parabas en la tribuna con veinte monos y la ganabas peleando. Ibas el martes al entrenamiento y decías "Ahora la manejo yo, quiero tanto por mes, tanto carnet, etc.". Ahora tenés que conseguir los contactos, los teléfono de uno, el otro, la yuta, ${ }^{21}$ el comisario, el dirigente, y ellos te van a decir que sí o que no. Además te sacan fotos, te escrachan en el Facebook, los periodistas... no es tan fácil.
\end{abstract}

Las capacidades de combate no desaparecen como recursos valorados de liderazgo. Se necesita "carácter" y "maldad" para manejar una barra, de acuerdo con el relato de Mauro. La referencia a la "historia" o la "trayectoria" reafirma la lógica del "aguante", de una corporalidad resistente a las penurias físicas y los golpes recibidos, cristalizada en el anecdotario de "viajes".

El quiebre temporal, sin embargo, marca una discontinuidad fundamental con las prácticas generacionales previas. Antes la barra se ganaba "peleando en la tribuna", ahora se la gana "tejiendo redes" dentro y fuera de los estadios. El desplazamiento de la violencia hacia afuera de los estadios está indisolublemente ligado a esta transformación en los criterios grupales de valorización. En un estadio violento el uso de la fuerza opera como el principal recurso legitimador. En cambio, en un estadio pacificado -e hipertecnologizado- la "cabeza" y los "contactos" emergen como los recursos más cotizados para los hinchas con pretensión de asumir posiciones de conducción y jerarquía.

\title{
REFLEXIONES FINALES
}

La historia del Polaco condensa sentidos sobre una hinchada fuertemente normativizada y autorregulada: una organización "democrática" y una violencia "limpia” y de "señores." A diferencia de los períodos subsiguientes la violencia física no aparece positivizada axiológicamente como recurso legitimo para la

\footnotetext{
${ }^{21}$ Categoría nativa que nombra a la policía.
} 
resolución de conflictos y la acumulación de prestigio. La descripción del presidente de la barra opera como evidencia sintomática.

Esto no significa que las prácticas violentas no existan en el relato de la generación del Polaco. La violencia tiene un doble sentido identitario. Por un lado afirma una identidad de género: enfrentamientos entre "hombres", entre "caballeros". Aquí la caballerosidad se define por mecanismos civilizatorios de regulación ${ }^{22}$ a partir de un universo moral asociado al "honor" en el combate y a la "cultura deportiva" tributaria de los valores del amateurismo: el "juego limpio", la representación de la alteridad como adversario antes que como enemigo, la tajante división de ámbitos ("es solamente fútbol"), el rechazo del lucro y la trampa, entre otros.

Por otro lado, los sentidos caballerescos de la violencia operan allí como diacrítico generacional. En los tiempos que suceden a aquella generación fundante toman importancia las motivaciones "económicas" y el incremento de los enfrentamientos caracterizados por el uso de armas blancas y de fuego. Tanto la economización de los lazos como la letalidad de la violencia emergen moralmente a contrapelo de los códigos normativos que caracterizaban a Los Piratas del 68. Mientras que el ingreso de intereses "espurios" rompe con los valores de la cultura deportiva amateur, las armas quiebran los códigos de honor de los antiguos "señores" que peleaban "limpiamente" con la sencillez de sus puños.

Las narraciones de Carlos describen, entre la década de 1980 y principios de la década de 2000, un mundo anómico y caótico en la hinchada de Belgrano. Ante esta lógica interna fuertemente desregulada en relación al orden anterior, la violencia física comienza a ganar terreno como principio estructurador del nuevo universo interno de la hinchada y la noción de "aguante" emerge como comodín explicativo para este contexto. La "cultura del aguante" entendida como una cultura de la violencia funciona como matriz organizadora de todo el repertorio de prácticas y representaciones propias de la hinchada.

Si bien la violencia continúa significando un recurso identitario de genero fundamental, los modelos de masculinidad en los que anclan las periodizaciones generacionales difieren entre sí: los procesos de diferenciación entre la generación

${ }^{22}$ ELIAS. El proceso de civilización. 
del Polaco y la de Carlos se sintetizan en el mentado paso de "una ética de caballeros a una ética de hombres y machos". 23

Al mismo tiempo, la violencia -la capacidad de "aguante"- funcionan como principal recurso legitimante que estructura las jerarquías organizacionales de la hinchada en los relatos de la segunda generación: en la barra, el prestigio y el respeto se dirimen por el "aguante", acumulado sólo a partir de la participación sucesiva en enfrentamientos violentos y "viajes" donde se ponen a prueba las competencias corporales de idoneidad para la pelea, la resistencia física para las adversidades y capacidad de consumo de sustancias (alcohol y droga). En un orden social nativamente definido como "descontrolado", los "barderos" logran revertir el estigma y traducirlo en signo de prestigio y marca identitaria de liderazgo en la organización de la barra.

La ambivalencia en las apreciaciones de Carlos sobre la legitimidad del uso de la violencia física y su doble estándar moral para juzgar a sus coetáneos y a la generación más joven se manifiesta como síntoma de un momento bisagra o de crisis en el que muda la interdependencia constitutiva entre la estructura organizativa de la hinchada, los sentidos de la violencia y los patrones de legitimidad que organizan el simbolismo interno de la barra. La ambigüedad discursiva de Carlos se vuelve certeza en los relatos de Mauro. Las significaciones de la tercera generación ponen en evidencia la manera en la que los umbrales de tolerancia a la violencia se trastocan al ritmo de una reconfiguración organizativa interna.

LPCA se erige como garante de un orden con altos umbrales de intolerancia a las transgresiones que ocurrían en los años precedentes. El contexto de una tribuna relativamente pacificada se corresponde con un organigrama interno que no sufre disputas ni cuestionamientos importantes de su representatividad ni de la legitimidad de su líder.

En un contexto pacificado, con reinserción de la familia, las tradiciones y la festividad en el estadio, la estigmatización del robo en la hinchada y la ausencia de las hinchadas de los equipos rivales visitantes, la violencia se desplaza espacial y simbólicamente, sin desaparecer: "la barra ya no se gana peleando". Retoman valor

\footnotetext{
${ }^{23}$ ALABARCES. Diagnóstico y propuestas para la construcción de una seguridad deportiva en Argentina.
} 
las capacidades organizativas, las redes de "contactos", las competencias intelectuales y logísticas, y se revitalizan patrones de legitimación como la asiduidad y el compromiso personal en las tareas de la barra. Se vive una suerte de retorno las notas discursivas de la generación del Polaco, la de Los Piratas del 68. Sin embargo, el recurso a la violencia persiste en el razonamiento de Mauro acerca de la necesaria "maldad" para "manejar" la barra. La reputación continúa dependiendo de la ostentación de "balazos de goma”, "quebradas" y "peleas". Tener "historia" en la barra continua implicando "tener aguante".

Los patrones de legitimación en la hinchada no desaparecen, sino que sedimentan y se resignifican a la luz de cada contexto histórico y sus respectivas periodizaciones nativas. "El pasado" se repite, se actualiza, se resignifica, se silencia, pero siempre opera, siempre resuena de alguna manera. Los recursos no se eliminan ni se inventan de la nada, sino que sus pesos relativos se acomodan y la estructuración del universo moral muta otorgando la materia prima a partir de la cual las fronteras generacionales y la memoria histórica de la hinchada se producen.

\section{REFERÊNCIAS}

ALABARCES, Pablo et al. Diagnóstico y propuestas para la construcción de una seguridad deportiva en Argentina. Ímpetus: Revista de la Universidad de los Llanos, Barcelona, vol. 7, n. 8, 2013, p. 59-65.

ALABARCES, Pablo. Crónicas del aguante: fútbol, violencia y política. Buenos Aires: Capital Intelectual, 2004.

ARCHETTI, Eduardo. Fútbol y ethos. Buenos Aires: FLACSO, [s.d.]. (Monografías e Informes de Investigación, 7).

CONDE, Mariana. La invención del hincha en la prensa periódica. In: ALABARCES, Pablo et. al. Hinchadas. Buenos Aires: Prometeo, 2006, p. 21-39.

ELIAS, Norbert; SCOTSON, John. Os estabelecidos e os outsiders: sociologia das relações de poder a partir de uma pequena comunidade. Río de Janeiro: Jorge Zahar, 2000.

ELIAS, Norbert. El proceso de civilización: investigaciones sociogenéticas y psicogenéticas. Buenos Aires: Fondo de Cultura Económica, 1993.

FRYDENBERG, Julio. Historia social del fútbol del amateurismo a la profesionalización. Buenos Aires: Siglo Veintiuno Editores, 2011. 
GARRIGA ZUCAL, José. Haciendo amigos a las piñas: violencia y redes sociales de una hinchada de fútbol. Buenos Aires: Prometeo, 2007.

GIL, Gastón. Hinchas en tránsito: violencia, memoria e identidad en una hinchada de un club del interior. Mar del Plata: Eudem, 2007.

JELIN, Elizabeth. Los trabajos de la memoria. Buenos Aires: Siglo XXI, 2002.

MOREIRA, Verónica. Trofeos de guerra y hombres de honor. In: ALABARCES, Pablo et al. Hinchadas. Buenos Aires: Prometeo, 2005. p. 75-90.

ROMERO, Amílcar. Muerte en la cancha, 1985-1985. Buenos Aires: Nueva América, 1986.

SPIERENBURG, Pieter. Violencia, castigo, el cuerpo y el honor, una revaluación. In: WEILER, Vera (Ed.). Figuraciones en proceso. Bogotá: Universidad Nacional de Colombia, 1998. p. 116-151. 